\title{
Value of Serum Sclerostin in Osteopenia and Osteoporosis Associated with Liver Cirrhosis and Post Liver Transplantation
}

\author{
Wael A.Yousry¹, Maha M. Hussein¹, Manal M. Mohsen², Safwat W. ${ }^{3}$ \\ Mohamed Abou El-EZZ ${ }^{3}$ \\ ${ }^{1}$ Internal Medicine department, Ain Shams University \\ ${ }^{2}$ Clinical Pathology department, Ain Shams University \\ ${ }^{3}$ Theodor Bilharz Reearch Institiute
}

\begin{abstract}
:
Background: Osteodystrophy is one of the signs of liver cirrhosis. In general, maintenance of bone over time requires balance between the formation of new bone tissue and breakdown and removal of old bone tissue. This balance is maintained by a variety of hormones. One of them is sclerostin.Sclerostin is an osteocyte-derived negative regulator of bone formation. It inhibits osteoblastic proliferation and differentiation and promotes osteoblast apoptosis.

Aim of the work: Evaluation of serum sclerostin level in relation to osteopenia \&osteoporosis in patients with liver cirrhosis and in patients who underwent liver transplantation.

Subjects and Methods:The study included (72) male patients who were divided into 3 groups:

Group I: Sixteen male patients with compensated liver cirrhosis (Child Pugh class A)

Group II: Thirty two patients with decompensated liver cirrhosis (Child Pugh class B and C)

Group III: Twenty four patients who underwent liver transplantation done at least one year before enrolment.For all patients; serum sclerostine level, calcium phosphorus,parathyroid hormone levels were measured, in addition to Dexa scan.

Results: Serum sclerostin level was present in highest concentration in group II (33.99 $\pm 13.8 \mathrm{ng} / \mathrm{ml})$ compared to group I $(15.01 \pm 1.87 \mathrm{ng} / \mathrm{ml}) \&$ group III patients $(9.98 \pm 1.12 \mathrm{ng} / \mathrm{ml})$. Osteoporosis and osteopenia were significantly most frequent in Child $B$ and $C$ patients (59.4\%) compared to Child A (25.1\%)and patients post liver transplantation (12.5\%).Serum sclerostin level was highest in osteoporotic patients (36.24 $\pm 11.9 \mathrm{ng} / \mathrm{ml})$, followed by osteopenic patients $(30.17 \pm 11.7 \mathrm{ng} / \mathrm{ml})$. Patients with normal Dexa scan had the lowest serum sclerostin level $(14.91 \pm 10.7 \mathrm{ng} / \mathrm{ml})$.

Conclusion: sclerostin is a good predictor for presence of bone diseases in patients with liver cirrhosis.It has sensitivity of $80.8 \%$ at serum level $\geq 17.7 \mathrm{ng} / \mathrm{ml}$
\end{abstract}

Keywords: sclerostin, cirrhosis,osteodystrophy, liver transplantation

\section{Introduction}

Hepatic Osteodystrophy is a generic definition for the metabolic bone disease that may occur in individuals with chronic liver disease[1]. Low body mass index (BMI), alcoholism, malnutrition, sedentary lifestyle with physical inactivity are behavioral factors often present in patients with chronic liver disease, and are connected with reduced bone mineral density(BMD), development of osteopenia/osteoporosis, and increased fracture risk[2].Low levels of insulin-like growth factor-1 (IGF-1)and low level of Osteoprotegerin (OPG) with decline in liver functions in cirrhotic patientsare other contributing factors,[3].Sclerostin is an osteocyte-derived negative regulator of bone formation. Sclerostin inhibits osteoblastic proliferation and differentiation and promotes osteoblast apoptosis[4].Sclerostin has been identified as binding toLRP5/6 receptors and inhibiting the Wnt signaling pathway. The inhibition of the Wnt pathway leads to decreased bone formation[5,6].It is suggested that circulating sclerostin is higher in patients with advanced liver cirrhosis than in healthy persons or patients with early liver cirrhosis. The relationship between circulating sclerostin and liver function indicates a possible role of the liver in sclerostin metabolism [7].

\section{Aim Of The Work}

Evaluate serum sclerostin as an indicator ofosteopenia \&osteoporosis in patients with different stages of liver cirrhosis and in patients who had underwent liver transplantation.

\section{Subjects And Methods}

This is a cross sectional study conducted in Ain Shams University Hospital. It included 72 male patients with chronic HCV infection. Patients were divided into 3 groups: 
Group I: Sixteen patients with compensated liver cirrhosis (Child Class A)according to Child and Turcotte classification[8].

Group II: Thirty two patients with decompensated liver cirrhosis (Child Class B and C).

Group III: Twenty four patients who underwent liver transplantation at least one year before enrolment.Exclusion criteria included: female patients, diabetes mellitus,renal impairment, thyroid diseases, hepatocellular carcinoma, liver cirrhosis due to causes other than viral hepatitisand rheumatological diseases as ankylosing spondylitis.

The study was explained to all patients and they were asked to sign consent before enrollment.

Medical history, clinical examination, basic laboratory investigations were done to all patients. In addition, measurement of serum sclerostin, serum calcium, phosphorus and parathyroid hormone was done.

Imaging studies icluded: pelvi-abdominal ultrasound, triphasic CT abdomen and pelvis (in cases of suspected hepatocellular carcinoma) and Dual energy X-ray absorptiometry

(Dexa scan) to diagnose osteopenia and osteoporosis.

Serum Sclerostin:

Test principle: The microtiter plate provided in this kit has been pre-coated with an antibody specific to. Samples are then added to the appropriate microtiter plate wells with a biotin conjugated polyclonal antibody preparation specific for and Avidin conjugated to. Horseradish Peroxidase is added to each microplate well and incubated. Then a TMP substrate solution is added to each well. Only those wells that contain biotin conjugated antibody and enzyme conjugated Avidin will exhibit a change in colour. The enzyme substrate reaction is determined by the addition of sulphuric acid solution and the colour change is measured spectrophotometrically at a wave length of $450 \mathrm{~nm}$. The concentration of in the samples is then determined by comparing the O.D. of the samples to the standard curve.

Expected values: $(0.312-20 \mathrm{ng} / \mathrm{ml})$

\section{Statistical Analysis}

The collected data was revised, coded, tabulated and introduced to a PC using statistical package for social sciences (SPSS 15.0.1 for windows; SPSS Inc).Data was presented and suitable analysis was done according to the type of data obtained for each parameter.

\section{I- Descriptive Statistics:}

1. Mean, Standard deviation (+ SD) and range for parametric numerical data, while Median and Interquartile range (IQR) for non parametric data.

2. Frequency and percentage of non-numerical data.

II- Analytical Statistics:

1- ANOVA was used to assess the statistical significance of the difference of a parametric variable between means of more than two study groups.

2- Post Hoc test

$(1,2)=$ Statistically significant difference between (Child A), (Child B\&C) by post hoc test.

$(1,3)=$ Statistically significant difference between (Child A) and (Post- Liver Transplantation) by post hoc test.

$(2,3)=$ Statistically significant difference between (Child B\&C) and (Post- Liver Transplantation) by post hoc test.

2- Fisher's Exact Test was used to examine the relationship between two qualitative variables when the expected count is less than 5 in more than $20 \%$ of the cells.

3- Pearson Correlation Coefficient (r): Correlation was used as a measure of the strength of a linear association between two quantitative variables.

4- ROC Curve: The diagnostic performance of a test or the accuracy of a test to discriminate diseased cases from normal cases is evaluated using Receiver Operating Characteristic (ROC) curve analysis.

\section{Results}

Table (1)shows the difference between the three groups in mean age, BMI and laboratory data. Patients in group I had significantly better CBC, liver functions (PT, bilirubin and albumin) compared to group II. Patients in group III had significantly different platelets count, PT and albumin level compared to the other two groups. Calcium, phosphorus and PTH were not significantly different between the studied groups. Serum sclerostin level was highest in group II (patients with decompensated liver cirrhosis). It was lowest in group III (Post liver transplantation patients). The difference in serum sclerostin levels between all groups was significant (figure 1). Table (2) shows the results of Dexa scan in the three groups; patients with decreased bone density (osteopenia and osteoporosis) were present in $25.1 \%, 59.4 \%$ and $12.5 \%$ in group I, II and III respectively. Osteopenia and osteoporosis were significantly more frequent in group I and II patients' compared to group III (figure 2). 
In table (3), sclerostin level was studied and compared between patients with normal bone density, osteopenia and osteoporosis according to Dexa scan findings. The mean serum sclerostin level in patients with normal bone density was $14.91 \pm 10.7 \mathrm{ng} / \mathrm{ml}$. It was $30.17 \pm 11.7 \mathrm{ng} / \mathrm{ml}$ and $36.24 \pm 11.9$ for osteopenia and osteoporosis respectively. Mean serum sclerostin was significantly lower in normal bone density compared to osteopenia and osteoporosis.

Table (2):Demographic and laboratory data of all patients

\begin{tabular}{|c|c|c|c|c|c|c|}
\hline $\begin{array}{l}\text { Patients variables } \\
(\text { mean } \pm \text { SD) }\end{array}$ & $\begin{array}{c}\text { Child A } \\
\text { group I } \\
(n=16)\end{array}$ & $\begin{array}{l}\text { Child B\&C } \\
\text { group II } \\
(n=32)\end{array}$ & $\begin{array}{l}\text { Post Liver } \\
\text { Transplantation } \\
\text { group III } \\
(\mathbf{n}=\mathbf{2 4})\end{array}$ & ANOVA & P-Value & $\begin{array}{l}\text { Post-Hoc } \\
\text { Test }\end{array}$ \\
\hline Age (Ys) & $\begin{array}{l}44.30 \pm \\
5.57\end{array}$ & $48.12 \pm 4.71$ & $51.29 \pm 5.02$ & 9.343 & $0.000 * *$ & $\begin{array}{l}(1,2), \\
(1,3),(2,3)\end{array}$ \\
\hline $\operatorname{BMI}\left(\mathrm{kg} / \mathrm{m}^{2}\right)$ & $\begin{array}{l}28.26 \pm \\
3.25\end{array}$ & $27.46 \pm 2.58$ & $25.79 \pm 2.77$ & 4.244 & $.018^{*}$ & $(1,3)(2,3)$ \\
\hline TLC $\pm\left(4-11 ~ 10^{3} / \mathrm{ul}\right)$ & $\begin{array}{l}6.41 \pm \\
1.81\end{array}$ & $5.91 \pm 1.85$ & $6.39 \pm 1.81$ & .618 & .542 & \\
\hline Hemoglobin (13-17 g/dl) & $\begin{array}{l}14.65 \pm \\
1.35\end{array}$ & $11.42 \pm 1.85$ & $11.41 \pm 1.63$ & 22.824 & $0.000^{* *}$ & $(1,2),(1,3)$ \\
\hline Platelets $\left(150-45010^{3} / \mathrm{ul}\right)$ & $\begin{array}{l}156.50 \pm \\
48.20\end{array}$ & $\begin{array}{l}79.31 \pm \\
19.78\end{array}$ & $183.83 \pm 42.25$ & 63.822 & $0.000^{* *}$ & $\begin{array}{l}(1,2),(1,3), \\
(2,3)\end{array}$ \\
\hline PT\# (10-14 seconds) & $\begin{array}{l}11.13 \\
\pm .43 \\
\end{array}$ & $13.03 \pm 1.14$ & $11.88 \pm .69$ & 27.079 & $0.000^{* *}$ & $\begin{array}{l}(1,2),(1,3), \\
(2,3)\end{array}$ \\
\hline Bilirubin (0.1-1.2 mg/dl) & $.93 \pm .53$ & $2.46 \pm .55$ & $.97 \pm .38$ & 81.102 & $0.000 * *$ & $(1,2),(2,3)$ \\
\hline Albumin (3.5-5 g/dl) & $4.48 \pm .38$ & $2.84 \pm .43$ & $3.98 \pm .31$ & 115.57 & $0.000 * *$ & $\begin{array}{l}(1,2),(1,3), \\
(2,3)\end{array}$ \\
\hline $\begin{array}{l}\text { Creatinine (0.4-1.4 } \\
\mathrm{mg} / \mathrm{dl})\end{array}$ & $.80 \pm .16$ & $.93 \pm .27$ & $1.09 \pm .27$ & 6.446 & $.003 * *$ & $(1,3),(2,3)$ \\
\hline $\operatorname{RBS}^{ \pm \pm}(70-140 \mathrm{mg} / \mathrm{dl})$ & $\begin{array}{l}112.93 \pm \\
18.1\end{array}$ & $119.1 \pm 23.5$ & $114.95 \pm 16.7$ & .586 & .559 & \\
\hline Calcium (8.1-10.4 mg/dl) & $9.04 \pm .62$ & $8.78 \pm .45$ & $8.95 \pm .61$ & 1.382 & .258 & \\
\hline $\begin{array}{l}\text { Phosphorous (2.7-4.9 } \\
\mathrm{mg} / \mathrm{dl})\end{array}$ & $3.57 \pm .49$ & $3.97 \pm .43$ & $3.88 \pm .44$ & 4.075 & 0.7 & \\
\hline PTH\#\# (8.8-76.6 pg/ml) & $\begin{array}{l}23.32 \pm \\
8.86\end{array}$ & $25.77 \pm 8.38$ & $27.87 \pm 7.29$ & 1.510 & .228 & \\
\hline $\begin{array}{l}\text { Sclerostin (0.31-20 } \\
\mathrm{ng} / \mathrm{ml})\end{array}$ & $\begin{array}{l}15.01 \pm \\
1.87\end{array}$ & $33.99 \pm 13.8$ & $9.98 \pm 1.12$ & 50.755 & $.000^{* * *}$ & $(1,2),(2,3)$ \\
\hline
\end{tabular}

(\#) Pro-thrombin Time (\#\#) Parathyroid Hormone(+) Total Leucocytic Count (++) Random Blood Sugar

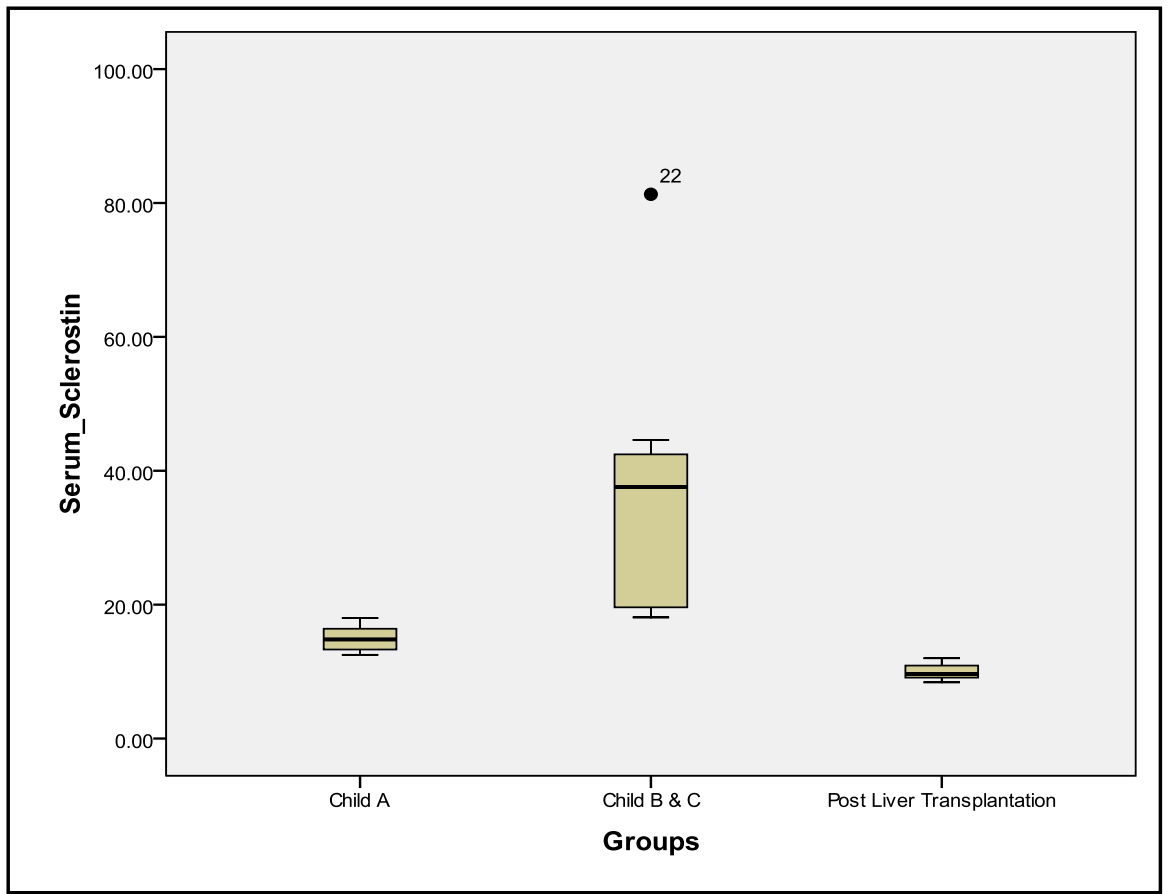

Figure (1): Comparison between the 3groups (Child A, Child B\&C, Post Liver transplantation) as regard serum sclerostin 
Alue Of Serum Sclerostin In Osteopenia And Teoporosisassociated With Liver..

Table (2):Comparison betweenDexa scan findingin the three groups \#

\begin{tabular}{|l|l|l|l|l|l|}
\hline DEXA Scan & $\begin{array}{l}\text { Child A } \\
(\mathbf{n = 1 6})\end{array}$ & $\begin{array}{l}\text { Child B\&C } \\
(\mathbf{n = 3 2})\end{array}$ & $\begin{array}{l}\text { Post Liver } \\
\text { Transplantation } \\
(\mathbf{n = 2 4})\end{array}$ & $\begin{array}{l}\text { Total } \\
(\mathbf{n}=\mathbf{7 2})\end{array}$ & \multirow{2}{*}{ P-value } \\
\cline { 1 - 5 } Normal (n \&\%) & $12(75 \%)$ & $13(40.6 \%)$ & $21(87.5 \%)$ & $46(63.9 \%)$ & \multirow{2}{*}{$0.005 * *$} \\
\cline { 1 - 5 } Osteopenia (n \&\%) & $1(6.3 \%)$ & $7(21.9 \%)$ & $2(8.3 \%)$ & $10(13.9 \%)$ & \\
\cline { 1 - 5 } Osteoporosis (n \&\%) & $3(18.8 \%)$ & $12(37.5 \%)$ & $1(4.2 \%)$ & $16(22.2 \%)$ & \\
\hline
\end{tabular}

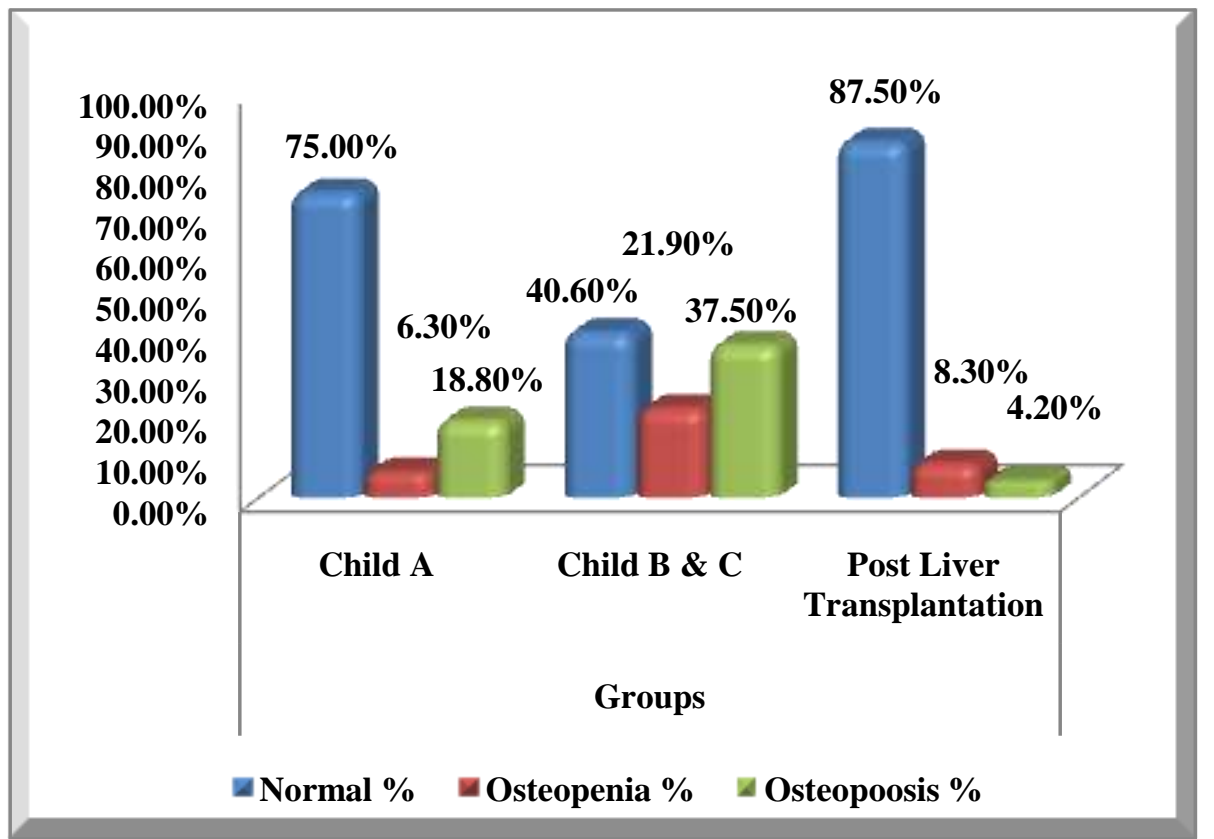

Figure (2): Dexa scan findings in the 3 groups (Child A, Child B\&C, Post Liver transplantation)

Table (3):Mean serum sclerostin level in patients with normal, osteopenic and osteoporoticbone density

\begin{tabular}{|l|l|l|l|l|l|l|}
\hline & Normal(n=46) & Osteopenia(n=10) & Osteoporosis(n=16) & ANOVA & P-Value & Post-Hoc Test \\
\hline $\begin{array}{l}\text { Sclerostin } \\
(\text { mean } \pm \text { SD) } \\
\mathbf{0 . 3 1 - 2 0 ~} \mathbf{~ n g} / \mathbf{m l}\end{array}$ & $14.91 \pm 10.7$ & $30.17 \pm 11.7$ & $36.24 \pm 11.9$ & 24.840 & $.000^{* *}$ & $(1,2),(1,3)$ \\
\hline
\end{tabular}

ROC curve was plotted (figure 3) to show the accuracy of sclerostinin differentiating osteopenia or osteoporosis from normal bone density (table $4 \& 5$ ). It showed that $87.8 \%$ of the patients with osteopenia or osteoporosis had an abnormal test result when compared to patients with normal bone density. The best cut off sclerostin level is $\geq 17.7 \mathrm{ng} / \mathrm{ml}$ at which sensitivity is $80.3 \%$ but specificity is only $28.3 \%$.

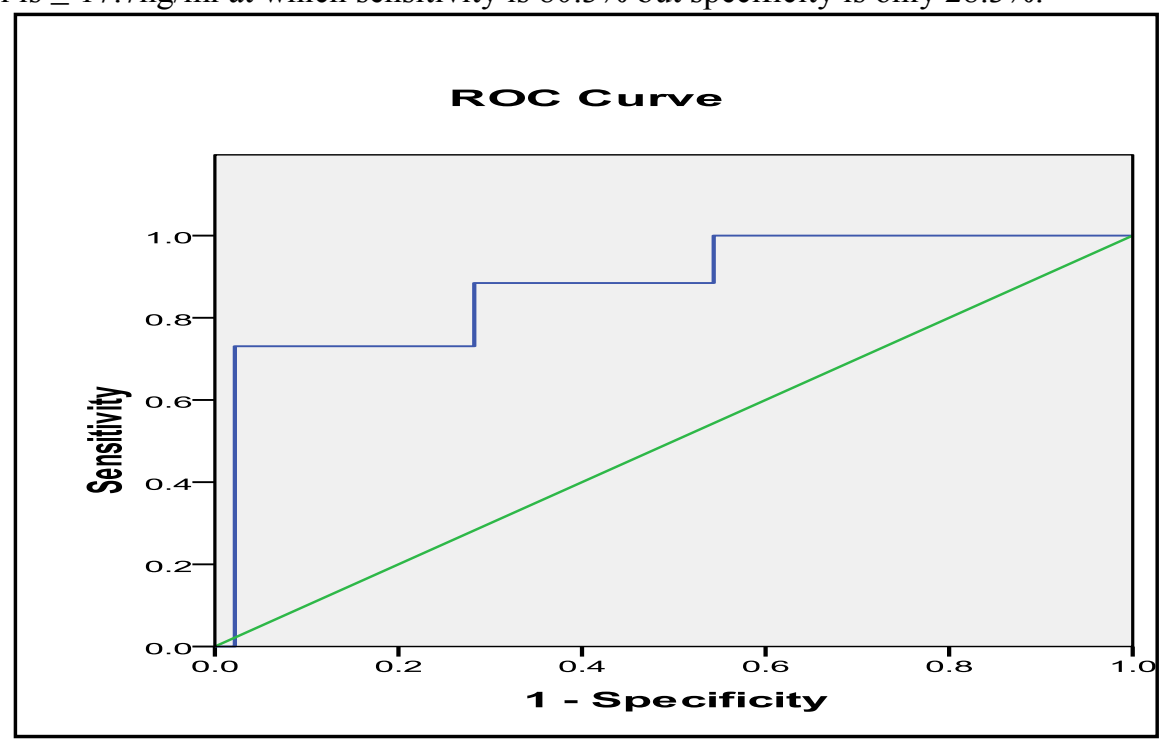

Figure (3): ROC curve forcutoff point of sclerostin to differentiate osteopenia or osteoporosis from normal bone density 
Alue Of Serum Sclerostin In Osteopenia And Teoporosisassociated With Liver ..

Table (4):Serum sclerostinaccuracyin differentiating osteopenia or osteoporosis from normal bone density

\begin{tabular}{|c|c|c|c|c|}
\hline Area & Std. Error & Asymptotic Sig. & \multicolumn{2}{|c|}{ Asymptotic 95\% Confidence Interval } \\
\cline { 4 - 5 } & & & Lower Bound & Upper Bound \\
\hline .878 & .044 & .000 & .793 & .963 \\
\hline
\end{tabular}

Table (5):Cut off point of sclerostin for differentiating osteopenia or osteoporosis from normal bone density in all studied patients

\begin{tabular}{|c|c|c|}
\hline Positive if Greater Than or Equal To ${ }^{\mathbf{a}}$ & Sensitivity & Specificity \\
\hline $17.700 \mathbf{~ n g / m l}$ & .808 & .283 \\
\hline
\end{tabular}

Table (6): Predictors of osteoporosis or osteopenia in studied patients

\begin{tabular}{|c|c|c|c|c|c|c|}
\hline \multirow[t]{2}{*}{ Predictors } & \multirow[t]{2}{*}{ B } & \multirow[t]{2}{*}{ Wald } & \multirow[t]{2}{*}{ Sig. } & \multirow[t]{2}{*}{$\operatorname{Exp}(B)$} & \multicolumn{2}{|c|}{ 95\% C.I. for $\operatorname{EXP}(B)$} \\
\hline & & & & & Lower & Upper \\
\hline CBC Hb & .098 & .095 & .758 & 1.103 & .592 & 2.052 \\
\hline CBC Platelets & .020 & 2.610 & .106 & 1.021 & .996 & 1.046 \\
\hline Total Bilirubin & .720 & .681 & .409 & 2.053 & .372 & 11.337 \\
\hline Serum Albumin & -1.058 & .565 & .452 & .347 & .022 & 5.485 \\
\hline PT & -.458 & .583 & .445 & .633 & .195 & 2.048 \\
\hline Serum_Creatinine & .439 & .046 & .829 & 1.551 & .029 & 83.960 \\
\hline Serum Calcium & -1.629 & 2.475 & .116 & .196 & .026 & 1.492 \\
\hline Serum_Sclerostin & .122 & 5.270 & $.022 *$ & 1.130 & 1.018 & 1.254 \\
\hline Constant & 15.048 & 1.280 & .258 & 3431093.680 & & \\
\hline
\end{tabular}

Logestic regression analysis showed that the only significant independent predictor for the occurrence of osteoporosis or osteopenia in the study population wassclerostin (table 6).

\section{Discussion}

The study showed that serum sclerostin was present in significantly highest concentration in patients with decompensated liver cirrhosis (Child B and C). It was higher in group I (Child A) compared to group III patients who underwent liver transplantation one year or more before enrollment.

The elevated serum sclerostin with advanced cirrhosis indicates a possible role of the liver in sclerostin metabolism. It can be one of the etiological factors of bone osteodystrophy which occurs with liver cirrhosis.

As liver transplantation is associated with recovery of liver functions and reversal of the sequale of liver cirrhosis including bone osteodystrophy, sclerostin level is found lowest among patients who had liver transplantation for more than one year (group III). It may also indicate improved sclerostin metabolism following liver transplantationand thus its level decreased.

In our study, there was no statistically significant difference in serum calcium, phosphorus and PTH in all groups. A finding that may be explained by body homeostatic mechanisms which keep constant blood chemistry as possible especially as we excluded patients with renal impairment (patients with renal impairment may show secondary hyperparathyroidism, low or normal serum calcium level and hyperphosphatemia).

In patients with decompensated liver cirrhosis, high level of sclerostin was associated with most frequent cases of osteopenia and osteoporosis $37.5 \%$ and $21.9 \%$ respectively. Patients with compensated liver cirrhosis had osteopenia in $6.3 \%$ and osteoporosis in $18.8 \%$ of cases, while patients with liver transplantation showed only $8.3 \%$ cases had osteopenia and $4.2 \%$ had osteoporosis. We can conclude that patients with liver cirrhosis have progressive decrease in bone density with progression of the disease. However, liver transplantation is associated with improvement of bone density. Thus, bone density is affected by the integrity of liver functions and it improves or partially recovers after liver transplantation.

Similarly,González-Reimers and his colleagues reported that serum sclerostin level was within the normal range in HCV non cirrhotic patients[9]while Rhee and his colleagues showed that Child B and C had higher serum sclerostin than patients with Child A [10].

Ninkovic and his coworkers also found that there wasa high prevalence of osteoporosis in patients with chronic liver disease prior to transplant [11].They conducted their study on 64 cirrhotic patients, $87 \%$ of them had hepatitis $\mathrm{C}$ virus and rest of patients had hepatitis B virus. In their study, $37.5 \%$ of patients were found to have osteopenia and $20.3 \%$ had osteoporosis.

The association between decrease bone density with increased sclerostin level was confirmed when we compared all patients who had osteoporosis and osteopenia with patients who had normal Dexa scan, where patients with bone disease had significant higher sclerostin level. We also found that $87 \%$ of patients with osteopenia and osteoporosis had abnormally high sclerostin level. So, sclerostin is at least one of the factors that deteriorate the bone status in patients with liver cirrhosis.

Ellieset al., explained the etiological role of sclerostin in osteopenia and osteoporosis by the fact that sclerostin was identified to bind to LRP5/6 receptors and inhibit the wnt signaling pathway and thus leading to decreased bone formation [12]. 
In general,sclerostin levels show a positive correlation with bone mineral diseases and increased bone breakdown[9].

Our results showed that the serum sclerostin level $\geq 17.7 \mathrm{ng} / \mathrm{dl}$ has $80.8 \%$ sensitivity to detect patients with abnormal Dexa scan among the studied subjects. Sclerostin was the only predictor of decreased bone density among those patients.

In conclusion, liver disease may impair sclerostin metabolism. The pathogenesis of bone disease in patients with liver cirrhosis may be- in part- related to impaired sclerostin metabolism. The severity of bone loss is related to the severity of underlying liver disease. Bone density seems to recover on long term following liver transplantation.Sclerostin inhibitorsmaybe a future target for treatment of bone disorders.

\section{References}

[1]. Sanchez AJ and Aranda-Michel J (2013). Liver disease and osteoporosis. Nutr Clin Pract.;21(3):273-8.

[2]. Goel V and Kar P(2010). Hepatic osteodystrophy. Trop Gasroenterol, 31: 82-6.

[3]. Toussaint ND, Elder GJ, and Kerr PG (2010). A rational guide to reducing fracture risk in dialysis patient. semin Dial. 23:43-54.

[4]. Burgers TA and Williams BO (2013). "Regulation of Wnt/B-catenin signaling within and from osteocytes.Bone. 54(2):244-9.

[5]. Van der Horst G, Van BezooiJen RL, Svensson JP and others (2007). J bone miner res. Jan, 22(1):19-28.

[6]. Collier J., (2007). Bone disorders in chronic liver disease. Hepatology 46:1271-7.

[7]. Child CG, Turcotte JG (1964). "Surgery and portal hypertension". In Child CG. The liver and portal hypertension. Philadelphia: Saunders. pp. 50-64

[8]. González-Reimers E, López-Prieto J, Pelazas-González R and others (2014).Serum sclerostin in hepatitis C virus infected patients. J Bone Metab; 21(1):69-75.

[9]. Rhee Y, Kim WJ, Han KJ and others (2014). Effect of liver dysfunction on circulating sclerostin. J Bone Miner Metab; 32(5)545-9.

[10]. Ninkovic M., Collier J. D., and Compston J. E. (2002). "Guidelines on the management of osteoporosis associated with chronic liver disease," Gut, vol. 50, no. 1, pp. 1-9,. Calcif Tissue Int 57(1): 15-9.

[11]. Ellies DL, Church V, Francis-West P and others.,(2000). The WNT antagonist cSFRP2 modulates programmed cell death in the developing hindbrain. Development127: 5285-95. 